right of being present (but not voting) at all after laborious inquiry, and devoting much meetings of the members."

Resolution 3.-Moved by Dr. Marshall Hall; seconded by SePt. Read, Esq.,

"That petitions be presented to her Majesty and both Houses of Parliament, praying for a measure of medical reform on the principles of incorporation, representation, uniform examinations, registration, and protection to the public against unqualified practitioners; and also that no charters be granted to any medical corporations until the whole subject shall have been brought before Parliament, and ample time allowed for discus. sion and consideration."

In moving this resolution, Dr. Marshall Hall successively commented on the different principles contended for. "In principle (said he) I am a free-trader, not trading, however, in the lives of my fellow-creatures. From such delinquencies the public ought to be protected." He wished for an universal galvanic machine, or rather telegraph, to rouse up the whole profession from their apathy, and desired nothing better than that it might depend on his hand to set the whole in motion.

After a few words on the apathy of the profession from Dr. Evans Riadore, the following petitions and report were read :-

To the Queen's most excellent Majesty.

The humble Petition of the President, Vice-President, Council, and Members of the British Medical Association, agreed to at their half-yearly Meeting on the 9th of May, 1813 :

Humbly showeth,-That your Majesty's principal Secretary of State for the Home Department has announced his intention of introducing into Parliament during the present session a Bill to Regulate the Education and Government of the Medical Profession; and believing that such a measure, on an enlarged and liberal basis, would be highly conducive to the health of your Majesty's subjects, and would be gratefully received by medical practitioners; but understanding that previous to the introduction of such Bill your Majesty will be recommended to grant new charters to the Royal Colleges of Physicians and Surgeons in London, which might have the effect of prejudging the question of medical reform,

Your petitioners humbly pray,-That your Majesty will be graciously pleased not to grant charters to any medical corporation until the expected measure shall have been laid before Parliament, and have received ample publicity and discussion. And your petitioners, \&c.

To the Honourable the Commons, \&c. (or the Lords, \&c.)

The Petition of the President, \&c., of the British Medical Association,

Humbly showeth,-That your petitioners, time and attention to the present state of the laws respecting the medical profession and its institutions, are convinced that they urgently reouire amendment; that your peti. tioners have on several occasions petitioned your honourable House for a measure of me. dical reform, upon a just and liberal basis, as regards the public and medical practitioners; that they have learned that her $\mathrm{Ma}$. jesty's principal Secretary of State for the Home Department has signified his inten. tion of bringing in a Bill to regulate and govern the medical profession, but that he may previously recommend her Majesty to grant charters to the Colleges of Physicians and Surgeons, for the former of which a Bill may be brought before your honourable House; that your petitioners believing that the granting of charters to these or any other institutions, without full discussion and in. quiry into the whole subject of medical re. form, will be prejudging the question, and might be highly injurious to the interests and privileges of the general practitioners, who form the great body of the medical profession, humbly pray,

That no measure be entertained by your honourable House, with reference to grantIng a charter to the Royal College of Physi. cians, nor that any other measure of partial medical legislation be taken into considera. tion by your honourable House, until the whole subject of medical reform is brought before Parliament, and have received full publicity and discussion.

And your petitioners further pray that no measure of medical reform be passed by your honourable Honse which does not contem. plate

1st. The institution of uniform searching examinations, both theoretical and practical, into the professional and general qualifications of candidates for the diploma, or right to practise all or any of the departments of the healing art, throughout her Majesty's dominions.

2nd. The union or incorporation into a representative faculty body (with equal rights and privileges) of all those so qualified, and of all present legally-qualified practitioners, who may wish to join the said F aculty of Medicine.

3.d. The registration of all qualified menbers of the profession, and protection to the public against unqualified practitioners.

\title{
REPORT OF THE COUNCIL ON MEDICAL RELIEF.
}

Soon after the anniversary meeting in No* vember last, the council again took into consideration the question of poor-law medical relief, with a view to the more just remune. ration of the medical officers, and thereby to 
secure a more efficient attendance on the sick poor.

To effect these and other objects connected with this all-important subject, the council resolved, that a deputation should once more wait on the commissioners; accordingly the deputation was appointed, and had a long interview with the commissioners at Somerset-house, of which they presented the fol. lowing report to the council, viz.:-

The deputation appointed at last council meeting report, that they had an interview with the poor-law cemmissioners on the 14th of February, 1843, and that it consisted of the president, Mr. Bottomley, of Croydon, Mr. Evans, Mr. Hooper, Mr. R. Read, Mr. Eales, and the hon. secretary.

Their objects were to impress on the commissioners,-

I. The necessity of increasing the amount of remuneration to the union medical officers, so that it should average at least 6s. 6d. for each case of sickness under their care; that sum to be increased in rural districts according to the distance, and lessened in densely populated districts, and in workhouses, but that the payment should rather be by a salary computed on the number of cases, and the distance, than by a separate sum for each case.

The commissioners did not consider that the payment per-case system could be carried ont, as what would be sufficient remuneration in one district would be very insufficient in another, and vice versd, and they thought that the plan would not work well for the poor nor the medical officers, as the guardians would be very careful to issue as few orders as possible. It was explained that these evils had been fully considered, and would be prevented or mainly obviated by the plans proposed for carrying out the system in detail. These were laid before the commissioners, but as it is difficult to convince those who have previously determined not to be convinced, the commissioners refused to accede to the proposals of the deputation, and on being closely pressed said they did not at present intend to make any farther alteration in the mode or amount of remuneration.

The deputation again reminded the commissioners that the present amount would not pay for a sufficient supply of the best drugs; that cheap and adulterated medicines were offered by chemists to union officers for the use of the poor; and that the temptation to employ these was almost irresistible under a system which allowed nothing for skill or attendance. Finally, in reply to a question of the deputation, the commissioners acknouledged that they had sufficient power under the present Act to enable them to increase the amount of remuneration to the medical officers, but they thought it would be opposed by the guardians, - they already objected to separate fees for operations and midwifery.

\section{Medical Supervision.}

The deputation then suggested the great importance of a plan of medical superintendence by means of a medical director and medical inspectors, under whose care the management and regulation of the poorlaw medical department should be placed; that such a plan would greatly facilitate proper arrangements for just remuneration to the medical officers, and other points which at present the commissioners accounted difficulties. The duties of the medical director would be (in conjunction with the commissioners) to issue general medical regulations, and to examine medical candidates; to hear appeals from union officers ; to arrange the size of medical districts ; and to prepare an annual report of the sanatory condition of the poor. The inspectors, who should be men of experience and standing in the profession, would see the general orders carried out; regulate the medical districts of the several unions under their charge; perhaps examine the qualities of the drugs employed for the poor; attend consultations when required by the medical officers; and present to the director quarterly, half-yearly, or anuual reports of their districts.

The commissioners objected to such a plan, not that it would be undesirable or objectionable, but that there was no machinery in the present Poor-law Act to carry it out; that on subjects requiring medical aid or advice they consulted gentlemen of talent and experience, as the various reports on fever and the sanatory condition of the poor, \&c., evinced. To this it was replied, first, that if there were no machinery in the present Act for a system of efficient medical supervision, it could easily be introduced in to the next Bill on the poor-law; second, that the profession objected to the employment of certain medical gentlemen, however eminent, whom the commissioners occasionally consulted, as this was done without responsibility on either side, and did not form that which was so desirable, viz., a continuous supervision and inspection.

This subject was discussed at considerable length.

\section{Size of Medical Districts.}

The deputation again drew the attention of the commissioners to the great size of some of the districts, and pointed out the importance of their being so reduced that the poor might quickly obtain medical aid, and the union officer have ready access to his patients.

The commissioners said that in many districts, such as in Wales and the north of England, they found it impossible to apportion the districts as they could wish from the poverty of practitioners; but in other cases they were reducing them, as far as 
circumstances would admit, and occasion required. They were reminded that the parliamentary witnesses had recommended the average size of rural districts to be from ten to twelve square miles, and in town districts that the population should not exceed 10,000 .

IV. Qualifications of Medical Officers.

The deputation cordially recognised the importance of union medical officers possessing both a medical and surgical qualification, at least until some efficient board was established, haring power to examine candidates in all departments of medical science. They, however, again protested against ths late order of the commissioners rendering it compulsory to obtain the surgical diploma from the London College, to the exclusion of the Edinburgh and Dublin Colleges. The commissioners stated, as on a former occasion, that they had acted under legal advice, and felt that they had no discretion in the matter; but to this it was replied, that Scotch and Irish surgeons were equally eligible with English ones, to the army and nayy, the East India Company's service, and the English jails, and that it was evidently in contravention of the Acts of Union.

\section{Choice of their Medical Attendants by the} Poor.

This plan, the details of which were fully laid before the commissioners, was again pressed upon their notice, as one that would afford the greatest degree of justice and satisfaction both to the poor and the profession.

The commissioners, after considerable discussion, said they could not give their approval to the plan, as it would lessen the value of the appointments, and they feared that the sume control could not be exercised over the medical oflicers ; but the deputation consider that they satisfactorily answered both these objections.

VI. Appointment of Medical Officers under the New Regulations.

The deputation inquired whether the commissioners intended to enforce their late medical order, as regarded the appointment of medical officers and the mode of remuneration, by fees, for operations, and in addi. tion to the salaries. The commissioners replied that they were fully resolved to do so, and that any appointment of a medical officer not in strict accordance with their order would not be sanctioned by them, and uould therefore be null and void.

VII. Medical Clubs.

It having been rumoured that the commis. sioners intended to issue an order for the formation of medical clubs throughout the unions, a question was put to them as to its truth.

The commissioners said that they had no intention of issuing any order respecting the formation of medical clubs.
The deputation, after applying for, and receiving each a copy of the last poor-law report, and thanking the commissioners for their courtesy and attention, withdrew.

From the above report it appears to the council, that though the commissioners have full power to issue and enforce such orders as they may see necessary for regulating all matters connected with the administration of medical relief, they are still resolved not to do that justice to the medical profession which they have so long been struggling to obtain, and that they are thereby neglecting their duty to the sick poor, by refusing to sanction such a moderate remuneration as would tend to secure adequate attendance and genuine medicines. The council will not enter upon the other points contained in the above report, as they have been frequently brought under the notice of the members, but recommend that an immediate appeal be made to Parliament and her Majesty's Government, praying for an amended system of medical relief.

Resolution 4.-Moved by Dr. Granville; seconded by R. L. Hooper, Esq.,

"That as in the opinion of this meeting the just rights and privileges of the great body of medical practitioners will not be secured without their union into a representative body or faculty of medicine, resolved that those associations and members of the profession who have not yet expressed their opinions on the subject, be invited to unite for this purpose with the British Medical and the other associations which have ren solved to form such a representative body or faculty."

Dr. Granville, in rising to propose this resolution, said, that he attributed the slow progress of reform not only to the apathy of the profession, but to the prevalence of petty jealousies among reformers themselves, who, instead of keeping steadily in view those radical principles of reform with which the British Medical Association had started, had indulged in all sorts of wild schemes and made all sorts of propositions both in orations and in letters. This kind of pro* ceeding might flatter the personal vanity of individuals, but was injurmons to the cause. He proceeded to say that he had been se. lected by the association to deliver the first oration, and he had in that, to the best of lis ability, laid down principles which he thought were to be the leading ones of reforners. These principles were the result of much inquiry and deliberation. He had digested the whole of the medical evidence given be. fore Parliament, and had out of the months of the corporations themselves showed the necessity of reform. He had in this oration shown the necessity of union in the main objects of reformers, the avoidance of all personal feelings and jealousies, of all frivolous distinctions, and of all petty differences of 
opinion. He believed that if the principles which he had adrocated in that oration had been firmly adhered to by all medical retormers, Sir J. Graham would not be in a condition to resist their just claims. But unfortunately reformers themselves did not agree, and as he had said all sorts of schemes had been proposed and suggested in letters and orations. He complained that in some quarters his labours had not been appreciated by reformers, and read an extract from his oration to show that he had claims of priority in proposing principles which were now not acknowledged to be of his originating.

R. L. Hooper, Esq., seconded the resolution. The council of the association had done their duty, and had met night after night, and year after year, to carry out the principles of reform for which the association had been formed. They had invited, and even implored, the profession out of doors to join them and assist them with their advice and subscriptions. The corporations took advantage of the disunited condition of reformers. He contrasted this want of union with the singleness of purpose of the chemists and druggists, from whose union and liberality of subscription we could receive an useful lesson.

Dr. WEBSTER, in putting the resolution to the meeting, remarked that this was not the time to discuss the claims to priority of reformers. Reform would and must triumph. Twenty-five years since it was merely as the well-spring hidden from the light of day; ten years ago it was as the small rivulet on which the sunlight shone; and six years since it began to receive tributary streams. He complimented Dr. Granville on the oration to which reference had been made, and proceeded to say that the association had not departed one iota from those principles which had been laid down at the first dimner of the association at the Bridge House Hotel, in 1836. If any deviation had been made, it was in the carrying a resolution this evening which proposed the formation of a faculty of medicine without any assistance from the corporate bodies, and totally independent of them. In the beginning these bodies had been applied to to assist in the formation of such faculty, but had not come forward to do so. It was now determined to form a faculty without them. He lamented the want of union among reformers, but such a want of union was natural, and to be expected, as persous might differ both as to the mode of reform and as to the extent to which it should be carried. The monopolists had only one object in view, and that was the retaining of their corporate monopolies, hence their union of opinion. The British Medical Association was not to blame for the want of union among medical men; the members of the whole profession had been exhorted to join them, and if they would not come forward in their own cause they deserved all the ill treatment they received from the corporations, and the bondage with which they were now enslaved. Opposed to this, he referred with pleasure to an evidence of union amoug reformers contained in a document issued by the Taunton and West Somersetshire Association. This document embodied a resolution that the members of that association should combine with the British and other medical associations to enrol themselves into a faculty of medical practitioner's of Great Britain, to watch over the future proceedings of Government and existing medical corporations on the subject of medical reform. A similar manifestation had been made by the Glasgow Association, and many such would be made during the next six months. Reform must triumph. (Cheers.)

Resolution 5.-Moved by R. Wallace, Esq.; seconded by Chas. Brady, Esq.,

"That the members of this association and of the profession be earnestly recommended to wait on their representatives and other members of both Houses of Parliament to explain to them the principles of medical reform, and to request that they will support the prayer of the petition of this association."

Resolution 6.-Moved by Gro. PILcher, Esq.; seconded by G. Botromsey, Esq., of Croydon.

"That the report of the council on the subject of medical relief be received and adopted, and that petitions be presented to both Houses of Parliament for an amended system of medical relief, particularly pray. ing for,-lst. A just scale of remuneration to the medical officers, so as to ensure adequate skill and attendance, and the best medicines. 2nd. A system of medical superintendence. 3rd. Equal rights to members of the Colleges of Surgeons of Edinburgh and Dublin with those of the London Colleges to be appointed medical officers of unions. And 4th. The choice of their medical attendants by the poor."'

George Pllcher, Esq., in proposing this resolution, referred to the petition, a document, as he considered, of great importance, not only to the profession, but to the poor. Much had been said respecting the want of union amongst medical men, but the absence of union was more the result of the circumstances under which many medical men were placed than of fault of their own. If contending interests rendered an unity of opinion impossible, that became a stropg argument in favour of legislative interference to assist the profession, by determining, after due inquiry, what was the best course of proceeding for all parties. He attributed much of the evil respecting the medical relief of the sick 
poor to the want of uniformity in the remuneration of medical officers; for in one district they were paid well, while in another they were actually out of pocket for expences for drugs and other necessaries. The whole blame rested with the poor-law commissioners, who ought not to reduce medical men to the necessity of accepting inadequate salaries, for he could not blame the medical officer, whether young or old, who, in the hope of making a connection, or retaining that practice which he had already acquired, consented to give his services to the poor, under the hope that something better might turn up in time. In many districts the medical officers were well paid, and it was necessary to show members of Parliament who might be guardians of those very unions that this was the exception and not the rule. This should be shown and proved. (Mr. Pilcher then adverted to the various points to which the resolution that he held in his hand referred.) The first of these, that which called for a just scale of remuneration, scarcely required comment. The second, which referred to the appointment of a medical superintendent, would, if acted upon, be serviceable to the profession, the poor, and the Government. He trusted that soon the distinction to which the third referred would be abolished, and that the education, the test of qualification, and the privileges of all British surgeons, would be the same; and, with regard to the fourth, he was sure that so humane a gift to the poor would be received by them with thankfulness, and that the plan recommended could be carried out easily by the poor-law commissioners without throwing additional expense on the rate-payers. (Hear, hear.)

G. Bottomley, Esq., of Croydon, seconded the resolution. Parliament might listen to the cause of the poor, if it did not to the claims of the profession, and the poor were as much interested in the purpose of this resolution as the profession itself. $\mathrm{He}$ was happy to say that the subject of medical relief had been taken up by some influential persons, both in and out of the profession, and that it was likely soon specially to occupy the attention of Parliament. He had been applied to respecting it, and had placed his opinions on paper. (Hear, hear.)

Towards the end of the proceedings a visitor, Mr. Rugg, made some remarks which caught a momentary attention from their pertinence to the objects of the meeting. When he was accustomed to attend the lectures of "the greatest medical reformer of the age," that functionary used to say, "In all things of importance take the bull by the horns!" Now that was precisely what he would say to the British Medical Association. Call yourselves a faculty at once, issue diplomas to your members. Invite the whole profession to join in the one body, and boldly call themselves "doctors," as members of the faculty. The Pharmaceutical Society made a similar stir,- they have already got incorporated by charter!

Dr. WEBSTER stated that the proposition of Mr. Rugg could not at that moment be entertained by the council, but the subject had been under its consideration for some time. The progress hitherto made by the associa. tion had been considerable, and he hoped that in six months time a faculty of medicine would be established by it.

Thanks were then voted to the president for his conduct in the chair, and the meeting separated.

ROYAL MEDICAL AND CHIRUR. GICAL SOCIETY.

Tuesday, April 25, 1843.

Edward Stanley, F.R.S., President.

Cases of Strangulated Hernia reduced en Masse, with Observations. By J. LuKE, Esq., Surgeon to the London and $\mathrm{St}$. Luke's Hospitals. (Communicated by Sir B. C. BRonie.)

IN this paper the object of the author is to show that the reduction of strangulated hernia en masse, although rare, is not so un. frequent as is generally supposed, and that the occurrence should be considered as com. ing within the ordinary range of probabili. ties of surgical practice. He had seen five cases of this description, two of which had been subject to his own treatment. In these the hernial tumour had been reduced en. tirely through the parietes into the abdo. minal cavity, with the contents strangu. lated; and as no swelling was perceptible, whilst the usual symptoms of strangulation continued, the diagnosis was rendered ex. tremely obscure. The author gives the details of the two cases which occurred in his own practice, and describes minutely the steps of the operation which he performed in each. In one case, owing to the deceptive nature of the symptoms, and absence of the external tumour, the operation was deferred too long, and the patient died. On examination, the hernial sac was found to occupy a considerable space just within the abdomi. nal parietes, in the vicinity of the abdominal ring. The fundus lay a little below its level, towards the pelvis, while the neck, still contracted, so as obviously to have been the original seat of stricture, was between three and four inches distant from the situation of the ring, and lay in an upward direction, to. wards the umbilicus. The whole sphace. lated contents were empty, collapsed, and in a pulpy state. In the second case the result of the operation was successful. In describ. ing its stages the author mentions, that before the hernial sac could be reached it was necessary to lay open the inguinal canal by dividing the tendon of the external oblique muscle, near the external ring; the spermatic cord was seen lying bare, or only covered 